\title{
Genome-wide analysis of maize OSCA family members and their involvement in drought stress
}

\author{
Shuangcheng Ding ${ }^{\text {Equal first author, 1,2 }}$, Xin Feng ${ }^{\text {Equal first author, 1 }}$, Hewei Du ${ }^{3}$, Hongwei Wang ${ }^{\text {Corresp. 1,2 }}$ \\ ${ }^{1}$ Agricultural College, Yangtze University, Jingzhou, China \\ 2 Hubei Collaborative Innovation Center for Grain Industry, Yangtze University, Jingzhou, China \\ 3 College of Life Science, Yangtze University, Jingzhou, China \\ Corresponding Author: Hongwei Wang \\ Email address: wanghw@yangtzeu.edu.cn
}

Background. Worldwide cultivation of maize is often impacted negatively by drought stress. Hyperosmolality-gated calcium-permeable channels (OSCA) have been characterized as osmosensors in Arabidopsis. However, the involvement of members of the maize OSCA (ZmOSCA) gene family in response to drought stress is unknown. It is furthermore unclear which ZmOSCA gene plays a major role in genetic improvement of drought tolerance in Maize. Methods. We predicted the protein domain structure and transmembrane regions by using the NCBI CDD database and TMHMM server separately. The phylogeny tree was built by Mega7. We used the mixed linear model in TASSEL to perform the family-based association analysis. Results. In this report, 12 ZmOSCA genes were uncovered in the maize genome by a genome-wide survey and analyzed systematically to reveal their synteny and phylogenetic relationship with the genomes of rice, maize and sorghum. These analyses indicated a relatively conserved evolutionary history of the ZmOSCA gene family. Protein domain and transmembrane analysis indicated that most of the $12 \mathrm{ZmOSCAs}$ shared similar structures with their homologs. The result of differential expression analysis under drought at various stages, as well as the expression profiles in 15 tissues, revealed a functional divergence of ZmOSCA genes. Notably, the expression level of ZmOSCA4.1 being up-regulated in both seedlings and adult leaves. Notably, the association analysis between genetic variations in these genes and drought tolerance was detected. Significant associations between genetic variation in ZmOSCA4.1 and drought tolerance were found at the seedling stage. Our report provides a detailed analysis of the ZmOSCAs in the maize genome. These findings will contribute to future studies on the functional characterization of ZmOSCA proteins in response to water deficit stress, as well as understanding the mechanism of genetic variation in drought tolerance in maize. 
1 Genome-wide analysis of maize $O S C A$ family members and their

2 involvement in drought stress

3 Shuangcheng Ding ${ }^{1,2,4}$, Xin Feng ${ }^{1,4}$, Hewei Du ${ }^{3}$, Hongwei Wang ${ }^{1,2}$

41 Agricultural College, Yangtze University, Jingzhou, China

52 Hubei Collaborative Innovation Center for Grain Industry, Yangtze University, Jingzhou,

6 China

73 College of Life Science, Yangtze University, Jingzhou, China

84 These authors contributed equally to this work

9

10 Corresponding Author:

11 Hongwei Wang

12 Nanhuan road 1, Jingzhou district, Jingzhou, Hubei, China

13 Email address: wanghw@yangtzeu.edu.cn 


\section{Abstract}

23 Background. Worldwide cultivation of maize is often impacted negatively by drought stress. Hyperosmolality-gated calcium-permeable channels (OSCA) have been characterized as osmosensors in Arabidopsis. However, the involvement of members of the maize OSCA $(\mathrm{ZmOSCA})$ gene family in response to drought stress is unknown. It is furthermore unclear which $\mathrm{ZmOSCA}$ gene plays a major role in genetic improvement of drought tolerance in Maize.

Methods. We predicted the protein domain structure and transmembrane regions by using the NCBI CDD database and TMHMM server separately. The phylogeny tree was built by Mega7. We used the mixed linear model in TASSEL to perform the family-based association analysis.

Results. In this report, $12 \mathrm{ZmOSCA}$ genes were uncovered in the maize genome by a genomewide survey and analyzed systematically to reveal their synteny and phylogenetic relationship with the genomes of rice, maize and sorghum. These analyses indicated a relatively conserved evolutionary history of the $\mathrm{ZmOSCA}$ gene family. Protein domain and transmembrane analysis indicated that most of the $12 \mathrm{ZmOSCAs}$ shared similar structures with their homologs. The result

of differential expression analysis under drought at various stages, as well as the expression profiles in 15 tissues, revealed a functional divergence of $\mathrm{ZmOSCA}$ genes. Notably, the expression level of $\mathrm{ZmOSCA4.1}$ being up-regulated in both seedlings and adult leaves. Notably, the association analysis between genetic variations in these genes and drought tolerance was detected. Significant associations between genetic variation in $\mathrm{ZmOSCA4.1}$ and drought tolerance were found at the seedling stage. Our report provides a detailed analysis of the $\mathrm{ZmOSCAs}$ in the maize genome. These findings will contribute to future studies on the functional characterization of ZmOSCA proteins in response to water deficit stress, as well as understanding the mechanism of genetic variation in drought tolerance in maize. 


\section{INTRODUCTION}

47 Drought stress is a key limiting environmental factor which can eventually cause food and

societal problems, and therefore numerous studies have been devoted to unraveling the mechanisms of drought resistance in plants. Studies over the past decades have found that plant responses to drought stress mainly include the perception, regulation, and transmission of signals through various pathways, as well as the regulation of stress-responsive gene expression (Ingram and Bartels 1996; Zhu 2002; Bartels and Sunkar 2005). As a consequence, physiological and morphological modifications result to address the stress. During the signal perception, especially during osmotic changes, calcium concentrations have been found to be elevated (Knight et al. 1997; McAinsh and Pittman 2009). Importantly, the increase in the concentration of $\mathrm{Ca}^{2+}$ occurs within five seconds, which might be the earliest detectable event in plants under stress (Knight et al. 1997). During the last three decades, studies have shown that $\mathrm{Ca}^{2+}$ is an important second messenger in the signal transduction process when plants respond to biotic and abiotic stress (Reddy 2001; Hepler 2005; Defalco et al. 2009). $\mathrm{Ca}^{2+}$-permeable channels have been proposed to function as osmosensors in bacteria and animals stimulated by osmotic/mechanical stress (Booth et al. 2007; Arnadottir and Chalfie 2010). Therefore, it can be inferred that $\mathrm{Ca}^{2+}$ is crucial for both sensing external osmotic stress and activating many signal transduction pathways.

Studies were carried out to find genes regulating early response to stress, especially the concentrations of calcium. When investigating the gene expression profile in Arabidopsis subjected to drought conditions, 16 early responses to dehydration $(E R D)$ genes were reported to be identified after one hour of drought stress (Kiyosue et al. 1994). Amongst the 16 ERDs, ERD4, harboring a highly conserved DUF221 domain (Pfam accession: 02714), was conserved between species (Camargo et al. 2007; Liu et al. 2009; Rai et al. 2012). Recently, using a gene screening strategy based on calcium imaging, an Arabidopsis hyperosmolality-gated calcium-permeable channel (OSCA) mutant was identified; oscal showed a low hyperosmolality-induced $\mathrm{Ca}^{2+}$ increase (OICI), and OSCAI was further characterized to be an osmosensor in Arabidopsis 
72 (Yuan et al. 2014). Interestingly, OSCA1 also contains the DUF221 domain. The results disclose

73

74 that DUF221 may participate in osmotic adjustment.

Association analysis, based on linkage disequilibrium (LD) and excavation of genetic variation, have been utilized as a novel strategy for dissecting the genetic basis of complex traits in crops (Yu and Buckler 2006). Drought tolerance is a complex and intrinsic trait, and the identification of favorable alleles for drought tolerance in maize through association studies, including candidate gene association analysis, is an ever-growing research area. Due to the rapid decrease in LD, association analysis in the maize genome could screen genetic variations at a single gene level. Although several genetic variations were found to enhance drought resistance (Liu et al. 2013; Mao et al. 2015; Wang et al. 2016; Xiang et al. 2017), allelic variations underlying drought tolerance still need to be identified to facilitate molecular breeding.

It has been shown that OSCA1 acts as an osmosensor in Arabidopsis (Yuan et al. 2014), and the role of the $O S C A$ gene family is essential for plants to respond to stress. Recently, genome-wide analysis of genes containing the DUF221 domain were performed in rice to understand its possible roles ( $\mathrm{Li}$ et al. 2015; Ganie et al. 2017). Therefore, in this study, we characterized the OSCA family members in the maize genome and analyzed the phylogenetic and syntenic relationship amongst these $O S C A$ s. In addition, we studied the expression profiles of $O S C A \mathrm{~s}$ under drought stress and performed a family-based genome-wide association study. These results could be applied for further functional research of $Z m O S C A$ s and raise our understanding of the roles of plant $O S C A \mathrm{~s}$ in drought stress.

\section{MATERIALS \& METHODS}

\section{Identification of OSCA protein-coding genes in the maize genome}


96 http://hmmer.janelia.org/) and scanned against the maize genome (genome assembly: AGPv3)

97 and the sorghum genome (genome assembly: V3). All the retrieved sequences were curated

98 using the NCBI Conserved Domain Database (CDD)

99 (www.ncbi.nlm.nih.gov/Structure/cdd/wrpsb.cgi) (Marchlerbauer et al. 2011) to determine

100 whether the proteins harbor the DUF221 domain or not.

\section{Genic structure and phylogenetic relationships analysis}

102 The protein sequences of the identified maize and sorghum OSCAs were downloaded from

103 Phytozome v10.0. The protein sequence of previously identified OSCA protein-coding genes in

104 the Arabidopsis and rice genome (Yuan et al. 2014; Li et al. 2015) were also downloaded form

105 Phytozome v10.0. To show the exon/intron structure, the coding sequence of each OSCA gene

106 were aligned to its corresponding genomic sequence and then a schematic representation was

107 generated using GSDS 2.0 (http://gsds.cbi.pku.edu.cn) (Hu et al. 2015). To construct a

108 phylogenetic tree of the identified OSCA proteins in rice, Arabidopsis, and sorghum, and maize

109 genome, ClustalW (Thompson et al. 1994) was used to align multiple protein sequences of

110 OSCA. The phylogenetic tree was constructed using this alignment output based on a neighbor-

111 joining method in MEGA7 (Kumar et al. 2016) using the following parameters: poisson

112 correction, pairwise deletion, uniform rates and bootstrap (1000 replicates).

113 Prediction of transmembrane region

114 TMHMM Server V2 was used to predict the transmembrane region (TMs) of ZmOSCAs, and the

115 prediction of TMs was manually edited according to the TMs of OSCA1.1, OSCA1.2 and

116 OsOSCA1.2 (Jojoa-Cruz et al. 2018; Liu et al. 2018; Maity et al. 2018; Murthy et al. 2018;

117 Zhang et al. 2018).

118 Gene duplication analysis

119 Chromosomal locations of $\mathrm{ZmOSCAs}$ were collected from the maize genome (assemble version: 
120

121

122

123

124

125

126

127

128

129

130

131

132

133

134

135

136

137

138

139

140

141

142

143

AGPv3) in Phytozome v10.0. The duplicated segmental blocks and gene pairs were analyzed on the Plant Genome Duplication Database (available online: http://chibba.agtec.uga.edu) with a display distance of 100 kilobases.

\section{Expression profile analysis}

Seedlings growth conditions and drought treatments of B73 (maize inbred line) were conducted according to Wang (Wang et al. 2016). Hydraulically cultured 3-leaf stage seedlings were put on a plate and subjected to dehydration $\left(40-60 \%\right.$ relative humidity and $\left.28^{\circ} \mathrm{C}\right)$. As for the effect of drought implied on adult leaf, drought stress was applied by withholding water after the eightleaf stage (V8), with well-watered plants (soil water content 40\%) as control. The middle section of flag leaf which came from three replicates, were collected at the twelve-leaf stage (V12), the fourteen-leaf stage (V14), the sixteen-leaf stage (V16) and the silking stage (R1) for both drought stressed and well-watered plants as control. Leaf samples from at least 3 replicates were frozen by liquid nitrogen and then stored at $-80^{\circ} \mathrm{C}$ before RNA isolation.

Raw RNA was extracted from leaf samples using TRI Reagent (Invitrogen, USA) according to the product manuals. The relative expression of $Z m O S C A s$ was quantified using quantitative real time-PCR (qRT-PCR). qRT-PCR was tested in 96-well plates using an ABI7500 Real-Time PCR Systems (Applied Biosystems, USA). The PCR reaction system consists of $1 \mu 1 \mathrm{cDNA}, 200 \mathrm{nM}$ primers, and $5 \mu \mathrm{l}$ SYBR Premix Ex Taq II (Takara, China), and the reaction volume was $10 \mu 1$. The PCR reaction was performed with the following conditions: $10 \mathrm{~min}$ at $94^{\circ} \mathrm{C}, 40$ cycles of 15 $\mathrm{s}$ at $94^{\circ} \mathrm{C}$, and $30 \mathrm{~s}$ at $60^{\circ} \mathrm{C}$. The internal control was the expression of $\mathrm{ZmUbi-2}$ (UniProtKB/TrEMBL; ACC: Q42415). The quantification method used was $2^{-\Delta C T}$, and the variation in the expression was derived from three biological replicates.

\section{Association Analysis}

Association analysis for $\mathrm{ZmOSCAs}$ was conducted by using a mapping population containing 
144367 maize inbred lines and corresponding drought resistance phenotypes reported previously 145 (Wang et al. 2016). The mapping population contains 556k single nucleotide polymorphism 146 (SNP) markers, and the minor allele frequency (MAF) of each marker was greater than or equal 147 to 0.05 . All identified ZmOSCAs harbored 168 SNPs in the coding region and both the 5'-, and 148 3'-untranslated region (UTR). Three statistical models including the general linear model (GLM) 149 model, adjusting the first two principal components $\left(\mathrm{PC}_{2}\right)$, and the mixed linear model (MLM) 150 model (incorporating $\mathrm{PC}_{2}$ and a Kinship matrix) were selected to identify the SNPs significantly 151 associated with drought resistance by using the TASSEL4.0 program ( Yu et al. 2006; Bradbury 152 et al. 2007).

153

\section{Identification of the $O S C A$ family members in maize}

We carried out a systematic genome-wide screen of putative $O S C A$ genes in maize. Initially, a Hidden Markov Model (HMM) search was performed against the maize genome (genome version: AGPv3.0) utilizing the DUF221 domain (Pfam accession: 02714). Ultimately, 12 genes were found to be $\mathrm{ZmOSCAs}$ in the maize genome and named according to the Arabidopsis orthologs (Table 1). The physical location of each ZmOSCA in the genome was identified according to physical coordination provided by MaizeGDB (https://www.maizegdb.org). Twelve $\mathrm{ZmOSCA}$ genes were distributed unevenly on all the ten chromosomes except chromosomes 2, 4, 7 and 10, without any clustering. Chromosomes 1 and 3 possessed as many as three ZmOSCA genes (the largest number of OSCA genes on a chromosome), and chromosomes 5 and 8 equally contained two genes. In contrast, chromosomes 6 and 9 each only harbored one ZmOSCA. The exon number of $\mathrm{ZmOSCAs}$ varied from 1 to 11 . Approximately $75 \%$ (8/12) of the $\mathrm{ZmOSCA}$ genes contained more than eight exons, and only $17 \%(2 / 12)$ of the genes had less than two exons.

\section{Phylogenetic relationship analysis of $O S C A$ genes}


169

170

171

172

173

174

175

176

177

178

179

180

181

182

183

184

185

186

187

188

189

190

191

192

193

194

In order to elucidate the phylogenetic relationships among $O S C A \mathrm{~s}$, a neighbor-joining tree of ZmOSCA proteins and the corresponding orthologs from rice, sorghum, and Arabidopsis was built, and the tree was based on the alignment of full-length OSCA proteins (Fig. 1; Table S1). As shown on the phylogenetic tree, 49 OSCA genes can be classified into four main classes, clades 1, 2, 3 and 4 (Fig. 1). All Arabidopsis and rice OSCAs fell in the same class or clade as previously reported, which is in agreement with previous work (Yuan et al. 2014). Interestingly, proteins derived from dicotyledonous Arabidopsis clustered separately from those of three monocot plants. Also, we found that some proteins from rice, sorghum and maize displayed pairwise correspondence (blue box in Fig 1), not only indicating that these genes are phylogenetically conserved among these species, but demonstrating that maize and sorghum possessed a closer phylogenetic relationship compared to maize and rice, conforming to the perspective that sorghum is a closer relative to maize than rice.

Throughout the phylogenetic tree, clades 1, 2, 3 and 4 contain 21, 20, four and four OSCA proteins, respectively (Fig. 1). Amongst the 49 OSCAs, there were 5, 5, 1, and $1 \mathrm{ZmOSCAs}$ in clades 1, 2, 3 and 4 respectively. However, for the rice and sorghum genomes, there were 4, 5, 1 and 1 OSCAs in clades 1,2, 3 and 4 respectively (Table 2). Obviously, compared with rice and sorghum, maize possessed one more $O S C A$ in clade 1 (Fig 1). Meanwhile, we detected the nodes that lead to maize-, sorghum- and rice-specific clades (red circles in Fig. 1). These nodes denote the divergence point between maize, sorghum, and rice, and therefore reveal the most recent common ancestral (MRCA) genes before the split. After MRCA analysis, there were 11 clades (indicated by red circles in Fig. 1), and nearly all the clades were constituted by one gene from the rice, maize, and sorghum genomes. However, there was just one clade that contained two genes from the maize genome (indicated by the red arrow in Fig. 1). The results showed that between the maize, sorghum, and rice genomes, the $O S C A$ gene family shared a similar evolutionary history, whilst the maize genome possessed a duplication event leading to a gain in one gene (indicated by red arrow in Fig. 1) after the maize, sorghum and rice genomes split. 
195

196

197

198

199

200

201

202

203

204

205

206

207

208

209

210

211

212

213

214

215

216

217

218

219

220

\section{Synteny of $O S C A$ s in maize, sorghum and rice genomes}

Gene collinearity comparative genomics indicates homologous gene function and phylogenetic relationships amongst several species and even the genome organization of extinct ancestral species. Thus, we investigated the colinearity of $O S C A$ genes in rice, sorghum, and maize genomes. Initially, gene colinearity data were retrieved from the Plant Genome Duplication Database using $Z m O S C A$ s as anchors, then the chromosomal segment containing multiple homologous genes across species was defined as a genomic syntenic block. After this analysis, $10 \mathrm{ZmOSCAs}$ were found to have collinearity, and the syntenic members or collinear genes in rice and sorghum were shown in Fig. 2. As a result, eight chromosomal segments containing $O S C A$ s were identified as being evolutionally conserved between rice, maize, and sorghum; these include ZmOSCA1.2, ZmOSCA1.3, ZmOSCA1.4, ZmOSCA2.2, ZmOSCA2.3, ZmOSCA2.4,

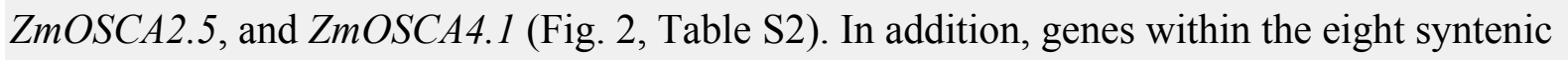
block amongst the maize, sorghum, and rice genomes were identical to the phylogenetic analysis (Fig. 1), confirming the accuracy of our analysis. Syntenic blocks of ZmOSCA1.1b and

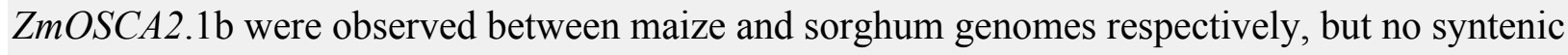
blocks of these genes were found between maize and rice genomes. Meanwhile, no collinear segments of $Z m O S C A 1.1 \mathrm{a}$ and $\mathrm{ZmOSCA3.1}$ were found in the genome of maize, rice, and

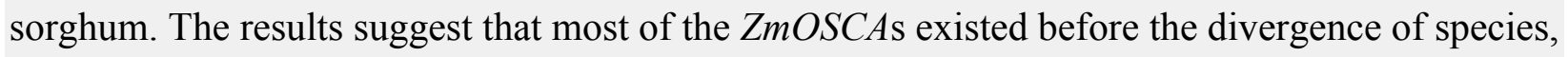
but some $Z m O S C A$ s may have originated from duplication of the maize genome.

\section{The conserved domain of ZmOSCAs.}

CDD was used to identify protein domains contained in ZmOSCAs. It was found that most ZmOSCAs harbored three domains except that ZmOSCA1.1a, ZmOSCA3.1, and ZmOSCA4.1 contained two domains (Fig. 3). It is noteworthy that DUF221 is located at the C-terminal of all $\mathrm{ZmOSCAs}$, indicating that this domain is not only necessary but also relatively conservative compared with other domains in the gene family. It was reported that there were $11 \mathrm{TMs}$ in the OSCA protein sequences (Jojoa-Cruz et al. 2018; Liu et al. 2018; Maity et al. 2018; Murthy et al. 
221

222

223

224

225

226

227

228

229

230

231

232

233

234

235

236

237

238

239

240

241

242

243

244

245

246

2018; Zhang et al. 2018). We found that half of the 12 ZmOSCAs had exactly 11 transmembrane regions (Fig. 3). A multiple sequence alignment was used to show the presence of TMs in DUF221 of ZmOSCAs (Fig. 4). It was found that protein domain DUF221 contained a different number of TMs, while protein domain pfam13967 contained a fixed number of TMs. However, no TMs were detected in the protein domain pfam14703 in ZmOSCAs. Different ZmOSCA members contained 2-7 TMs in the DUF221 region. Most of the ZmOSCAs contained at least eight TMs with two exceptions. ZmOSCA1.1a and ZmOSCA3.1 had fewer TMs than others, suggesting that a deletion event occurred for ZmOSCA1.1a and ZmOSCA3.1.

\section{Expression profiles of $\mathrm{ZmOSCA}$ genes under drought stress}

We studied the expression profiles of the $12 \mathrm{ZmOSCA}$ genes in 15 different tissues using the reported transcriptomic data (Sekhon et al. 2011). As shown in Fig. 5A, expression patterns of ZmOSCA genes varied greatly. Expression values of ZmOSCA1.1a, ZmOSCA1.1b, ZmOSCA1.2, and $Z m O S C A 4.1$ were relatively higher than the rest among the tissues tested. Previous studies have shown that OSCAs had key roles in different aspects of plant development, especially in stress responses ( $\mathrm{Li}$ et al. 2015). In order to obtain further insight into the roles of ZmOSCAs in drought tolerance, their expression profiles were monitored by quantitative real-time PCR analyses using three-week-old leaves of maize seedlings treated with drought stress for five hours or 24 hours. As shown in Fig. 5B, in the genotype of B73, more than half of expression level of the ZmOSCAs were regulated by drought stress, including six ZmOSCAs that were upregulated significantly and one down-regulated $Z m O S C A$; the others were hardly responsive to drought stress. In addition, genes showing up- or down-regulation were found unfavorably in each of the four major clades. The results showed that proteins from different clades might have overlapping and/or antagonistic functions in the regulation of drought responses in plants. Amongst the six up-regulated $\mathrm{ZmOSCA}$ genes, in comparison to normal growth conditions, the expression of ZmOSCA2.4 was induced more than six-fold, that being the largest folds change in relative expression levels (Fig. 5B). Five ZmOSCAs (ZmOSCA1.1b, ZmOSCA1.2, ZmOSCA1.4, 
247

248

249

250

251

252

253

254

255

256

257

258

259

260

261

262

263

264

265

266

267

268

269

270

271

272

ZmOSCA2.1, and ZMOSCA4.1) were up-regulated over two-fold in response to drought (Fig. 5B).

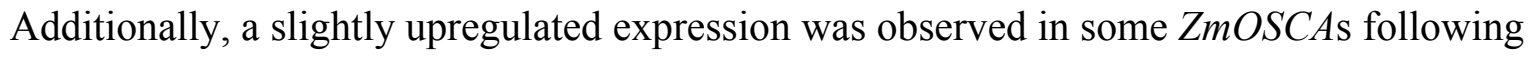
drought treatment for five hours or 24 hours; these include ZmOSCA1.1a, ZmOSCA2.2,

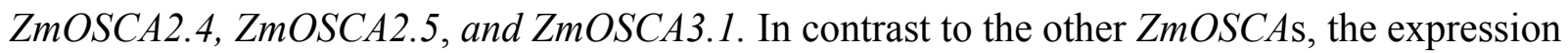
level of $\mathrm{ZmOSCA2.3}$ decreased about three-fold after drought treatment (Fig. 5B). Relative expression of $\mathrm{ZmOSCAs}$ were also detected in adult leaves at four growth stages, V12, V14, V16, and R1. Drought stress for the adult leaves was applied by withholding water at the V8 stage, while the corresponding control was well-watered (soil water content 40\%) plants. As shown in Fig. 6, five ZmOSCAs were up-regulated at least one stage, and one ZmOSCA was downregulated at two stages under drought. Across the four stages, the relative expression levels of

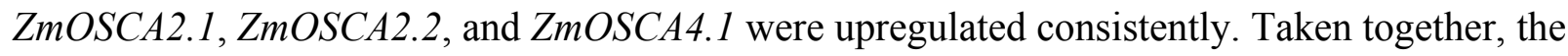

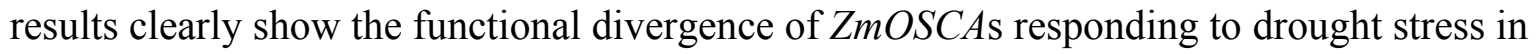
maize seedlings and adult leaves. Collectively, the data demonstrated that different $\mathrm{ZmOSCAs}$ showed variable expression patterns under drought stress, while the expression value of ZmOSCA4.1 was highly expressed in 15 tissues and up-regulated in both seedling and adult leaf by drought stress.

\section{Association analysis of genetic variations in $\mathrm{ZmOSCAs}$ with drought tolerance}

In order to further inquire whether the genetic variation in $\mathrm{ZmOSCAs}$ was associated with drought tolerance, a family-based association analysis was performed for these genes. At the seedling stage, the drought tolerance of the mapping population was assessed by evaluating seedling survival rate under severe drought stress. Based on previously reported methods and data (Liu et al. 2013; Wang et al. 2016), genetic polymorphism was characterized as the presence and number of SNP markers in each of the 12 ZmOSCAs. All the 12 identified ZmOSCAs were identified as polymorphic, with 14 SNPs on average for each identified gene (Table 3). As a consequence, ZmOSCA4.1 was identified as the second most polymorphic gene, with 34 SNPs in this mapping population. Subsequently, three statistical models were used to find out significant 
273

274

275

276

277

278

279

280

281

282

283

284

285

286

287

288

289

290

291

292

293

294

295

296

297

associations between genotype and phenotype. In brief, a general linear model (GLM), with the first two principal components $\left(\mathrm{PC}_{2}\right)$, and mixed linear model (MLM) incorporating both $\mathrm{PC}_{2}$ and a kinship matrix correcting the effect of cryptic relatedness were used in the associations. GLM method was used to conduct the single-marker analysis. $\mathrm{PC}_{2}$, via the first two principal components on SNP data, was utilized to adjust spurious associations resulted from population structure. MLM was regarded as an effective method for controlling false positives in association analysis (Yu and Buckler 2006; Yu et al. 2006). Subsequently, candidate gene association analysis identified significant associations between genetic variation of $\mathrm{ZmOSCA4.1}$ with drought tolerance under different models with a $P$-value $\leq 0.01$ (Table 3 ). The results appeared

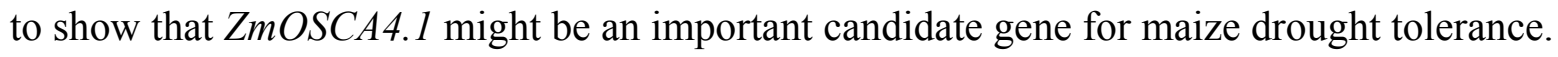

\section{DISCUSSION}

Previous study has indicated that OSCA1, containing the domain DUF221, is an osmosensor in Arabidopsis (Yuan et al. 2014). Subsequently, studies have been done to identify OSCA family members in Arabidopsis and rice, which lead to the identification of 15 AtOSCAs and 11 OsOSCAs respectively (Yuan et al. 2014; Li et al. 2015). However, no detailed analysis has been performed for the $O S C A$ gene family in maize, especially its expression profile under drought stress. Moreover, it is not yet known which $\mathrm{ZmOSCA}$ is directly associated with the diversity of drought tolerance in maize. Therefore, we carried out this study to address these questions. Our findings will provide fundamental factors that may be used to facilitate the genetic enhancement of drought tolerance in maize, as well as increase our understanding of the role of this gene family under drought.

In our study, we identified $12 \mathrm{ZmOSCAs}$ in maize, and then we systematically analyzed their phylogenetic and synteny relationship with rice, maize and sorghum genomes (Fig. 1; Fig. 2). After MRCA analysis, we found that the Arabidopsis genome possessed the largest number of OSCAs, whilst the maize genome possessed three gene losses compared to Arabidopsis and one 
298

299

300

301

302

303

304

305

306

307

308

309

310

311

312

313

314

315

316

317

318

319

320

321

322

323

324

gene gain compared to the rice genome. The number of $O S C A$ s within the maize, sorghum, and rice genomes did not vary much, indicating that the majority of $O S C A \mathrm{~s}$ in maize, sorghum, and rice genomes undergo relatively conserved evolutionary history after their divergence. As shown in Fig. 1, 12 maize genes were clustered into four clades as reported previously (Yuan et al. 2014). Gene numbers in clades 2,3 and 4 were identical between maize, sorghum and rice genomes. As shown in Fig. 1, the maize genome possessed one more $O S C A$, namely ZmOSCA1.1a, having the fewest number of exons in clade 1. But, in the synteny analysis, we did

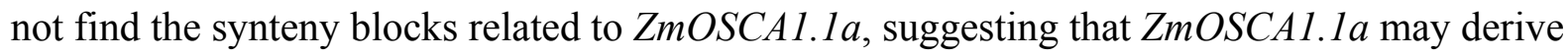
from duplication after the divergence of the maize, sorghum and rice genomes and possess functional differentiation from other ZmOSCAs. Meanwhile, we found that, despite ZmOSCA3.1, OsOSCA3.1 and Sobic.002G034500 were clustered together (Fig. 1), ZmOSCA3.1 was absent from the synteny analysis (Fig. 2). Interestingly, ZmOSCA3.1 was constituted by two exons. The results suggest that $\mathrm{ZmOSCA3.1}$ may exit before the maize, sorghum and rice genomes split, but evolved in a different direction from OsOSCA3.1 and Sobic.002G034500. Previos studies showed that there were $11 \mathrm{TMs}$ in the OSCA protein sequences (Jojoa-Cruz et al. 2018; Liu et al. 2018; Maity et al. 2018; Murthy et al. 2018; Zhang et al. 2018), and each OSCA protein in the Arabidopsis genome contained 11 TMs (Jojoa-Cruz et al. 2018). However, only half of the 12 ZmOSCAs had exactly 11 transmembrane regions, demonstrating that ZmOSCAs might possess a greater genetic variation during the evolution. Protein domain and transmembrane regions analysis also revealed that ZmOSCA1.1 $a$ and ZmOSCA3.1 contained fewer domains and TMs compared with others (Fig. 3; Fig. 4). Obviously, deletions in ZmOSCA1.1a and ZmOSCA3.1 occurred independently during maize evolution. However, both ZmOSCA1.1a and ZmOSCA3.1 did not respond to drought treatment, suggesting that they may not have a function in drought resistance.

To our knowledge, although the relationship between OSCA proteins and stresses has been reported (Zhao et al. 2015), the dynamic drought-responsive expression patterns of $\mathrm{ZmOSCAs}$ were still obscure. Expression pattern analysis of $Z m O S C A$ s helped us to understand their 
325

326

327

328

329

330

331

332

333

334

335

336

337

338

339

340

341

342

343

344

345

346

347

348

349

possible functions and offer a thorough foundation for future functional studies. Generally, ZmOSCAs exhibited differential expression under drought stress in maize seedlings and adult leaves, not only amongst sub-groups but also amongst members within the same sub-groups, suggesting that these $\mathrm{ZmOSCAs}$ may have diverse functions. Our results showed that the relative expression levels of six $\mathrm{ZmOSCAs}$ were significantly up-regulated and expression of one $\mathrm{ZmOSCA}$ was clearly down-regulated (Fig 5), indicating that these genes might serve as key mediators of drought stress responses. In other research, the relative expression of OsOSCA1.1, OsOSCA1.2, OsOSCA2.1, OsOSCA2.4, OsOSCA2.5, and OsOSCA4.1 were up-regulated by PEG treatment (Li et al. 2015). Interestingly, in this study, we found that six ZmOSCAs, including ZmOSCA1.1b, ZmOSCA1.2, ZmOSCA1.4,ZmOSCA2.1, ZmOSCA2.4, and ZmOSCA4.1, could be up-regulated by drought stress (Fig 5). When we analyzed the expression pattern of ZmOSCAs in adult leaves at four stages, ZmOSCA2.1, ZmOSCA2.2 and ZmOSCA4.1 were found to be upregulated consistently (Fig. 6) at both seedlings and adult leaf. Notably, the relative expression level of the rice orthologs of ZmOSCA2.1, ZmOSCA2.2 and ZmOSCA4.1 were also upregulated by drought stress ( $\mathrm{Li}$ et al. 2015), demonstrating that these genes may share a conserved function.

To date, no study is known of which detects the association between genetic variations in ZmOSCAs and drought tolerance. To answer this question, the genetic polymorphism amongst all of the $12 \mathrm{ZmOSCAs}$ were analyzed. Under the three models, ZmOSCA4.1 was consistently the most significantly associated with drought tolerance $(P$-value $\leq 0.01$, Table 3$)$. Furthermore, in response to drought stress, the expression of $\mathrm{ZmOSCA4.1}$ was induced, indicating that this gene might be engaged in resistance to drought stress. Further detailed analysis of biochemical and molecular functions of $\mathrm{ZmOSCA4.1}$ will contribute to our understanding of OSCA function.

\section{CONCLUSIONS}

In this report, $12 \mathrm{ZmOSCA}$ genes were uncovered in the maize. Synteny and phylogenetic 
350

351

352

353

354

355

356

357

358

359

360

361

362

363

364

365

366

367

368

369

370

371

372

373

relationship analyses were performed, and it was found that the ZmOSCA gene family shared a conserved evolutionary history. Protein domain and transmembrane analysis indicated that most of the $12 \mathrm{ZmOSCAs}$ shared similar structures with their homologs. Differential expression analysis under drought at various stages, as well as the expression profiles in 15 tissues, revealed a functional divergence of $\mathrm{ZmOSCA}$ genes. Notably, the expression level of ZmOSCA4.1 being up-regulated in both seedlings and adult leaves. Importantly, significant associations between genetic variation in ZmOSCA4.1 and drought tolerance were found at the seedling stage. Our research will enhance our understanding of the role of ZmOSCAs under drought.

\section{ACKNOWLEDGEMENTS}

The authors would like to thank Dr. Du for his critical reading the manuscript.

\section{REFERENCES}

Arnadottir J, Chalfie M. 2010. Eukaryotic mechanosensitive channels. Annual review of biophysics 39:111-137 DOI 10.1146/annurev.biophys.37.032807.125836

Bartels D, Sunkar R. 2005. Drought and Salt Tolerance in Plants. Critical reviews in plant sciences 24:23-58

Booth IR, Edwards MD, Black S, Schumann U, Miller S. 2007. Mechanosensitive channels in bacteria: signs of closure? Nature reviews. Microbiology 5:431-440 DOI $10.1038 /$ nrmicro 1659

Bradbury PJ, Zhang Z, Kroon DE, Casstevens TM, Ramdoss Y, Buckler ES. 2007. TASSEL: software for association mapping of complex traits in diverse samples. Bioinformatics 23:2633-2635 DOI 10.1093/bioinformatics/btm308

Camargo SR, Cancado GM, Ulian EC, Menossi M. 2007. Identification of genes responsive to the application of ethanol on sugarcane leaves. Plant cell reports 26:2119-2128 DOI $10.1007 / \mathrm{s} 00299-007-0430-8$ 
374

375

376

377

378

379

380

381

382

383

384

385

386

387

388

389

390

391

392

393

394

395

396

397

398

399

400

DeFalco TA, Bender KW, Snedden WA. 2009. Breaking the code: $\mathrm{Ca}^{2+}$ sensors in plant signalling. Biochemical Journal 425:27-40 DOI 10.1042/bj20091147

Finn RD, Bateman A, Clements J, Coggill P, Eberhardt RY, Eddy SR, Heger A, Hetherington K, Holm L, Mistry J, Sonnhammer EL, Tate J, Punta M. 2014. Pfam: the protein families database. Nucleic Acids Research 42:D222-230 DOI 10.1093/nar/gkt1223

Ganie SA, Pani DR, Mondal TK. 2017. Genome-wide analysis of DUF221 domain-containing gene family in Oryza species and identification of its salinity stress-responsive members in rice. PLoS One 12:e182469 DOI 10.1371/journal.pone.0182469

Hepler PK. 2005. Calcium: a central regulator of plant growth and development. Plant Cell 17:2142-2155 DOI 10.1105/tpc.105.032508

Hu B, Jin JP, Guo AY, Zhang H, Luo JC, Gao G. 2015. GSDS 2.0: an upgraded gene feature visualization server. Bioinformatics 31:1296-1297 DOI 10.1093/bioinformatics/btu817

Ingram J, Bartels D. 1996. The Molecular Basis of Dehydration Tolerance in Plants. Annual review of plant physiology and plant molecular biology 47:377-403 DOI 10.1146/annurev.arplant.47.1.377

Jojoa-Cruz S, Saotome K, Murthy SE, Tsui CCA, Sansom MSP, Patapoutian A, Ward AB. 2018. Cryo-EM structure of the mechanically activated ion channel OSCA1.2. eLife 7:e41845 DOI 10.7554/eLife.41845

Kiyosue T, Yamaguchi-Shinozaki K, Shinozaki K. 1994. Cloning of cDNAs for genes that are early-responsive to dehydration stress (ERDs) in Arabidopsis thaliana L.: identification of three ERDs as HSP cognate genes. Plant Molecular Biology 25:791-798 DOI $10.1007 / \mathrm{bf00028874}$

Knight H, Trewavas AJ, Knight MR. 1997. Calcium signalling in Arabidopsis thaliana responding to drought and salinity. Plant Journal 12:1067-1078 DOI 10.1046/j.1365313x.1997.12051067.x

Kumar S, Stecher G, Tamura K. 2016. MEGA7: Molecular Evolutionary Genetics Analysis Version 7.0 for Bigger Datasets. Molecular Biology and Evolution 33:1870-1874 DOI 
401

402

403

404

405

406

407

408

409

410

411

412

413

414

415

416

417

418

419

420

421

422

423

424

425

426

427

\subsection{3/molbev/msw054}

Li Y, Yuan F, Wen Z, Li Y, Wang F, Zhu T, Zhuo W, Jin X, Wang Y, Zhao H, Pei ZM, Han S. 2015. Genome-wide survey and expression analysis of the $O S C A$ gene family in rice. BMC Plant Biology 15:261 DOI 10.1186/s12870-015-0653-8

Liu S, Wang X, Wang H, Xin H, Yang X, Yan J, Li J, Tran LS, Shinozaki K, YamaguchiShinozaki K, Qin F. 2013. Genome-wide analysis of $Z m D R E B$ genes and their association with natural variation in drought tolerance at seedling stage of Zea mays L. PLoS Genetics 9:e1003790 DOI 10.1371/journal.pgen.1003790

Liu X, Wang J, Sun L. 2018. Structure of the hyperosmolality-gated calcium-permeable channel OSCA1.2. Nat Commun 9:5060 DOI 10.1038/s41467-018-07564-5

Liu YH, Li HY, Shi YS, Song YC, Wang TY, Li Y. 2009. A Maize Early Responsive to Dehydration Gene, ZmERD4, Provides Enhanced Drought and Salt Tolerance in Arabidopsis. Plant Molecilar Biology Report 27:542-548 DOI 10.1007/s11105-009-0119-y

Maity K, Heumann J, McGrath AP, Kopcho NJ, Hsu P-K, Lee C-W, Mapes JH, Garza D, Krishnan S, Morgan GP, Medrano-Soto A, Hendargo KJ, Klose T, Rees SD, Saier MH, Piñeros M, Komives EA, Schroeder JI, Chang G, Stowell MHB. 2018. Cryo-EM Structure of OSCA1.2 from Oryza sativa: Mechanical basis of hyperosmolality-gating in Plants. bioRxiv505453 DOI 10.1101/505453

Mao H, Wang H, Liu S, Li Z, Yang X, Yan J, Li J, Tran LS, Qin F. 2015. A transposable element in a NAC gene is associated with drought tolerance in maize seedlings. Nature Communications 6:8326 DOI 10.1038/ncomms9326

Marchlerbauer A, Lu S, Anderson JB, Chitsaz F, Derbyshire MK, Deweesescott C, Fong JH, Geer LY, Geer RC, Gonzales NR. 2011. CDD: a Conserved Domain Database for the functional annotation of proteins. Nucleic Acids Research 39:D225-D229

McAinsh MR, Pittman JK. 2009. Shaping the calcium signature. New Phytologist 181:275-294 DOI 10.1111/j.1469-8137.2008.02682.x

Murthy SE, Dubin AE, Whitwam T, Jojoa-Cruz S, Cahalan SM, Mousavi SAR, Ward AB, 
Patapoutian A. 2018. OSCA/TMEM63 are an evolutionarily conserved family of mechanically activated ion channels. eLife 7:e41844 DOI 10.7554/eLife.41844

Rai A, Suprasanna P, D'Souza SF, Kumar V. 2012. Membrane topology and predicted RNAbinding function of the 'early responsive to dehydration (ERD4)' plant protein. PLoS One 7:e32658 DOI 10.1371/journal.pone.0032658

Reddy AS. 2001. Calcium: silver bullet in signaling. Plant Science 160:381-404

Sekhon RS, Lin H, Childs KL, Hansey CN, Buell CR, de Leon N, Kaeppler SM. 2011. Genome-wide atlas of transcription during maize development. Plant Journal 66:553-563 DOI 10.1111/j.1365-313X.2011.04527.x

Thompson JD, Higgins DG, Gibson TJ. 1994. CLUSTAL W: improving the sensitivity of progressive multiple sequence alignment through sequence weighting, position-specific gap penalties and weight matrix choice. Nucleic Acids Research 22:4673-4680

Wang X, Wang H, Liu S, Ferjani A, Li J, Yan J, Yang X, Qin F. 2016. Genetic variation in ZmVPP1 contributes to drought tolerance in maize seedlings. Nature Genetics 48:1233-1241 DOI $10.1038 / \mathrm{ng} .3636$

Xiang Y, Sun X, Gao S, Qin F, Dai M. 2017. Deletion of an Endoplasmic Reticulum Stress Response Element in a ZmPP2C-A Gene Facilitates Drought Tolerance of Maize Seedlings. Molecular Plant 10:456-469 DOI 10.1016/j.molp.2016.10.003

Yu J, Buckler ES. 2006. Genetic association mapping and genome organization of maize. Current Opinion in Biotechnology 17:155-160 DOI 10.1016/j.copbio.2006.02.003

Yu J, Pressoir G, Briggs WH, Vroh Bi I, Yamasaki M, Doebley JF, McMullen MD, Gaut BS, Nielsen DM, Holland JB, Kresovich S, Buckler ES. 2006. A unified mixed-model method for association mapping that accounts for multiple levels of relatedness. Nature Genetics 38:203-208 DOI 10.1038/ng1702

Yuan F, Yang H, Xue Y, Kong D, Ye R, Li C, Zhang J, Theprungsirikul L, Shrift T, Krichilsky B, Johnson DM, Swift GB, He Y, Siedow JN, Pei ZM. 2014. OSCA1 mediates osmotic-stress-evoked $\mathrm{Ca}^{2+}$ increases vital for osmosensing in Arabidopsis. Nature 514:367- 
Zhang M, Wang D, Kang Y, Wu JX, Yao F, Pan C, Yan Z, Song C, Chen L. 2018. Structure of the mechanosensitive OSCA channels. Nat Struct Mol Biol 25:850-858 DOI

Zhao X, Xu M, Wei R, Liu Y. 2015. Expression of OsCAS (Calcium-Sensing Receptor) in an 460 Arabidopsis Mutant Increases Drought Tolerance. PLoS One 10:e0131272 DOI 10.1371/journal.pone.0131272

Zhu J. 2002. Salt and drought stress signal transduction in plants. Annual Review of Plant Biology 53:247-273

\section{FIGURE LEGENDS}

Figure 1. Phylogenetic tree and gene structure of predicted OSCA genes from maize, rice, sorghum, and Arabidopsis. (A) The phylogenetic tree of 49 full-length OSCA protein sequences from four species. The names used for OSCA gene in rice and Arabidopsis are according to Li et al., 2010. Each node was labeled with bootstrap values from 1,000 replicates. Genes contained in a blue-box were regarded as direct orthologous genes among species. (B) Position of exons, introns, and (untranslated region) UTR in the OSCA genes. Introns are indicated by lines, exons by black boxes, UTR by gray box.

Figure 2. Schematic diagram of syntenic chromosomal segments containing $Z m O S C A$ genes between the sorghum, rice, and maize genomes. $Z m, O s$, and $S b$ stand for chromosomes in maize,

474 rice, and sorghum respectively. The homologous chromosomal regions of different genomes are

475 connected by black dotted lines Each OSCA homologous gene pair is linked by a red line.

476 Yellow, blue and brown boxes represent the homologous regions within the maize, rice and 477 sorghum genome. 
478 Figure 3. Protein domains and transmembrane regions in ZmOSCAs. Protein domains and 479 transmembrane regions were predicted by CDD search and TMHMM. Black lines indicate the

480

transmembrane regions. The protein domains were colored according to the color legend.

Figure 4. Transmembrane region of the DUF221 in ZmOSCAs. DNAman and TMHMM were used to perform multiple sequence alignments and predicte transmembrane region. TM1-TM7 are the transmembrane regions that are marked by black lines. Regions between red lines Figure 5. Expression profiles of $\mathrm{ZmOSCAs}$. (A) Expression profiles of the $12 \mathrm{ZmOSCA}$ genes in fifteen tissues illustrated by a heat map. Different colors in the heat map represent the normalized gene expression values indicated by the scale bar. The color scale ranged from green, representing low expression, and passes through yellow and finally to red, representing high expression. The gray color shows missing data. (B) Expression profile of $Z m O S C A$ genes in maize B73 seedlings under drought. Total RNA was extracted from the third leaves before and after the drought treatments. 5 and 24 hours, represent the collection time points, responding to relative leaf water content (RLWC) of 70\% and 58\%, respectively. Transcript levels of ZmUbi-2 were used as an internal control for data normalization. The represented mean and SD derived from three biological replicates. $\left(t\right.$-test, $\left.{ }^{*} p \leqslant 0.05,{ }^{*} * p \leqslant 0.01\right)$

Figure 6. Expression patterns of $\mathrm{ZmOSCA}$ genes in maize B73 adult leaves under drought. The drought treatment started from the (eight leaves) V8 stage, while the control was well-watered. Total RNA was collected at V12, V14, V16 and R1 stage for both drought stressed and wellwatered plants. Transcript levels of $\mathrm{ZmUbi-2}$ transcript levels were used served as an internal control for data normalization. Data represent the represented mean and SD derived from of 
499 three biological replicates. $\left(t\right.$-test, $\left.{ }^{*} p \leqslant 0.05,{ }^{*}{ }^{*} p \leqslant 0.01\right)$.

500 Table 1. Detailed information for twelve ZmOSCA genes in the Zea mays L. genome.

501 Table 2. Numbers and classification of OSCA genes in Arabidopsis, rice, maize, and sorghum.

502 Table 3. Number of significantly associated genetic variation in $Z m O S C A$ genes with drought

503 tolerance at the seedling stage.

504 Supporting Information

505 Table S1. Gene and protein sequences used to construct phylogenetic tree.

506 Table S2. Collinear segments between maize, rice and sorghum genomes. 


\section{Figure 1}

Phylogenetic tree and gene structure of predicted OSCA genes from maize, rice, sorghum, and Arabidopsis

(A) The phylogenetic tree of 49 full-length OSCA protein sequences from four species. The names used for OSCA gene in rice and Arabidopsis are according to Li et al., 2010. Each node was labeled with bootstrap values from 1,000 replicates. Genes contained in a blue-box were regarded as direct orthologous genes among species. (B) Position of exons, introns, and (untranslated region) UTR in the OSCA genes. Introns are indicated by lines, exons by black boxes, UTR by gray box. 


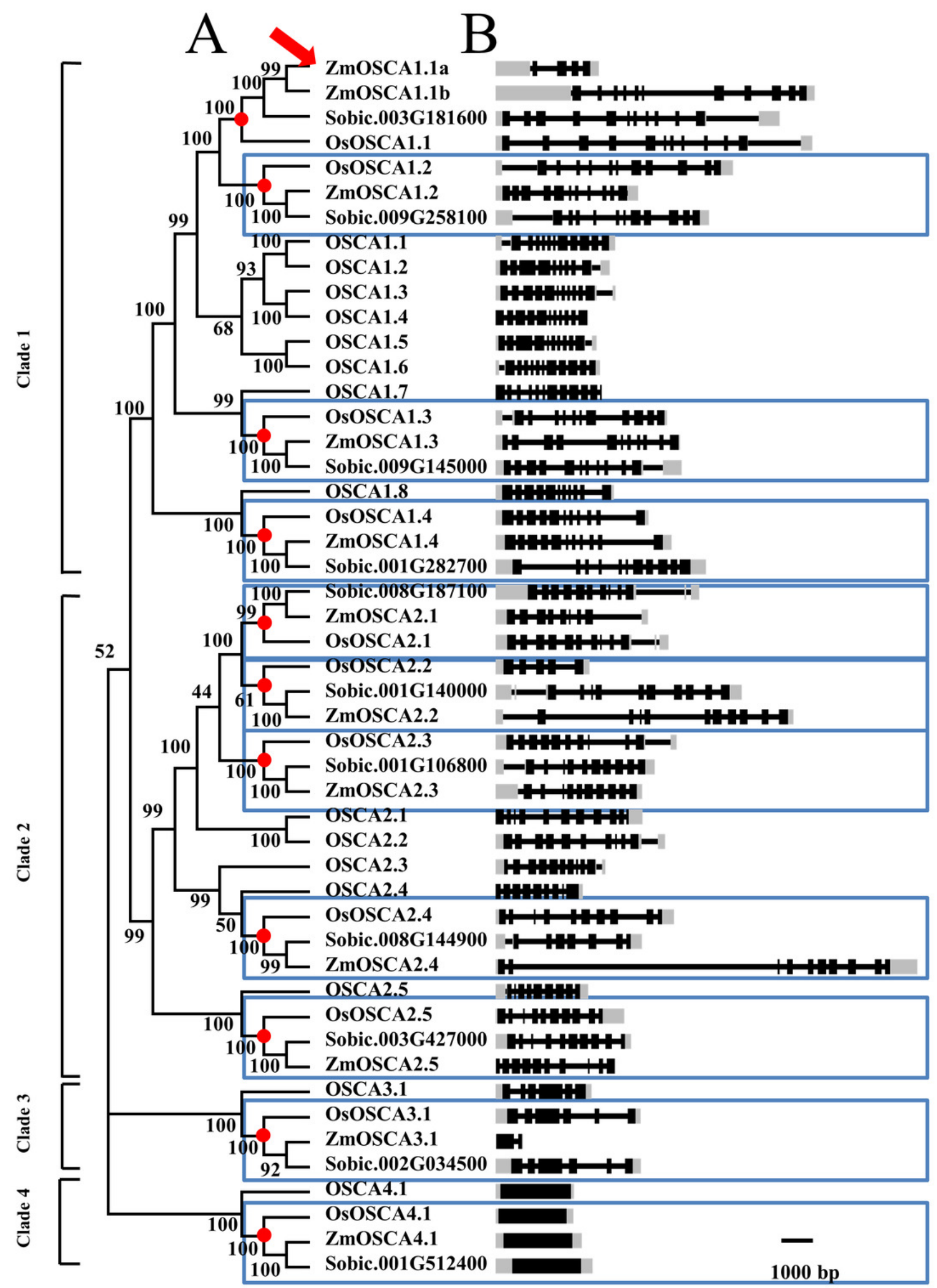




\section{Figure 2}

Schematic diagram of syntenic chromosomal segments containing ZmOSCA genes between the sorghum, rice, and maize genomes.

$Z m, O s$, and $S b$ stand for chromosomes in maize, rice, and sorghum respectively. The homologous chromosomal regions of different genomes are connected by black dotted lines Each OSCA homologous gene pair is linked by a red line. Yellow, blue and brown boxes represent the homologous regions within the maize, rice and sorghum genome.

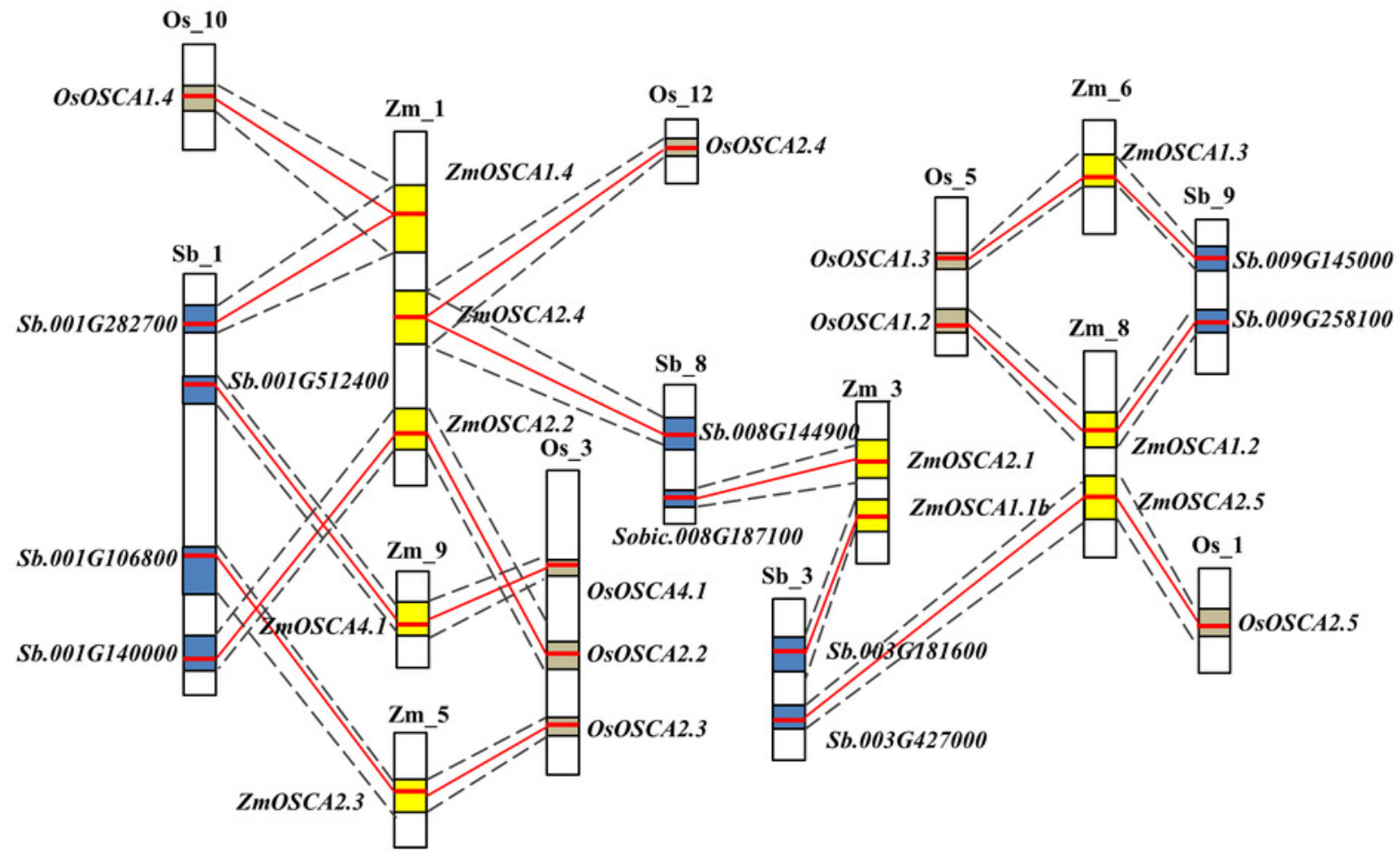




\section{Figure 3}

Protein domains and transmembrane regions in ZmOSCAs.

Protein domains and transmembrane regions were predicted by CDD search and TMHMM.

Black lines indicate the transmembrane regions. The protein domains were colored according to the color legend. 


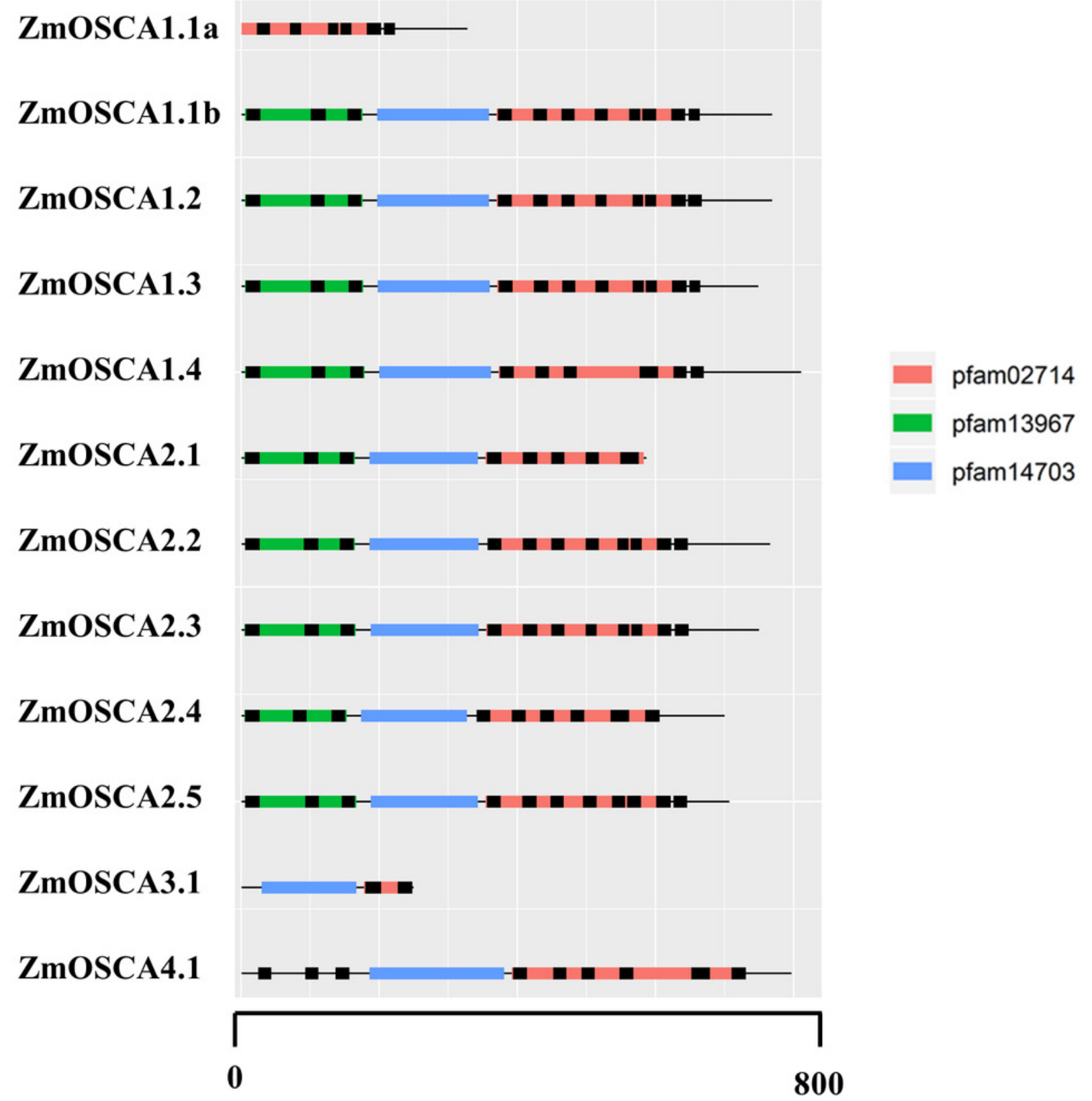


Figure 4

Transmembrane region of the DUF221 in ZmOSCAs.

DNAman and TMHMM were used to perform multiple sequence alignments and predicte transmembrane region. TM1-TM7 are the transmembrane regions that are marked by black lines. Regions between red lines 
ZmOSCA1.1a ZmOSCA1.1b ZmOSCA1.2 ZmOSCA1.3 ZmOSCA1.4 ZmOSCA2.1 ZmOSCA2.2 ZmOSCA2.3

ZmOSCA2.4 ZmOSCA2.5 ZmOSCA3.1 ZmOSCA4.1

ZmOSCA1.1a ZmOSCA1.1b ZmOSCA1.2 ZmOSCA1.3 ZmOSCA1.4 ZmOSCA2.1 ZmOSCA2.2 ZmOSCA2.3 ZmOSCA2.4 ZmOSCA2.5 ZmOSCA3.1 ZmOSCA4.1

ZmOSCA1.1a ZmOSCA1.1b ZmOSCA1.2 ZmOSCA1.3

ZmOSCA1.4 $\mathrm{ZmOSCA2.1}$

ZmOSCA2.2

$\mathrm{ZmOSCA2.3}$

ZmOSCA2.4

ZmOSCA2.5

ZmOSCA3.1

ZmOSCA4.1

ZmOSCA1.1a ZmOSCA1.1b

ZmOSCA1.2

ZmOSCA1.3

ZmOSCA1.4

ZmOSCA2.1

ZmOSCA2.2

ZmOSCA2.3

ZmOSCA2.4

ZmOSCA2.5

ZmOSCA3.1

ZmOSCA4.1

ZmOSCA1.1a ZmOSCA1.1b ZmOSCA1.2 ZmOSCA1.3 ZmOSCA1.4 ZmOSCA2.1

ZmOSCA2.2

ZmOSCA2.3

ZmOSCA2.4

ZmOSCA2.5

ZmOSCA3.1

ZmOSCA4.1

\section{TM1}

SIPFVSLT RRLIIAVAFFFLNFFYVFPIAFVOSLA $\ldots \ldots$ NLEGIEKAAPFLKPLIEEH. TIKSFTOG LSIPFVSLT RR LTVAVAFFFINFFYVTRTTEV QSLA . . . . . NLEGIEKALPFLKPLIDLP. F IKSF IOG LAIPFVELS RRLIVVAVAFFFITFFFMTPTATVQSLA . . . . . . NLDDIVKVLPFLKPIIERN . SLKSVIQGFF LAIPFFSLS RRELMSVAVFAIVFEYMTPTAEVQSLA . . . . . NLEGLEKVAPFLKFVIEAH. VVKSFL GE LWLPYKQLW RRIATLLGSIFFMFIFLIFVTFIOGLS . . . . . QLEQLQQRLPFLRGILKKKYYMTQLVTGY $\ldots . \ldots .$. RH IVTLMCSTVENVVELTEVTEIOGLT . . . . . QLEQLQQRLPFLRGILKKK. YMTQLITGY LWIPYRQIW RKLATLAASIVFMFVFIVEVAFV SMM . . . . . . . QLEQLKRMFPSLTGLLNKS. FFARVITGY $\ldots \ldots \ldots \ldots$ LIIIVELIVVAFVOGLT. . . . . . YLEQLEKWLPFLRNILEIA. VVSQIVTGY LSIPFWRMA YYRLGVEAAAVILTVEFTTIEVTAVQGIA . . . . . QFEKMKRWFPPARAVQLIP. GLNSVVTGY LPMKLYDRC RQ SVVYGIVEITVVVYYNVSLTAIFAVT . . . . . TLENLEK. LPFLKFVVEQP. AIKTVLEAY LGLSKISSR RRIAVNTCLILMLILESSBIAIISGMQNAARI INVEAMDHAKSWLAWLEGSS . WFWTIIFOF

\section{TM2}

\section{TM3}

.MFMSKVEGLTSISSLERRSASKYYTFIFFNVELASTIAGSATEQLKSYIHC_SAN

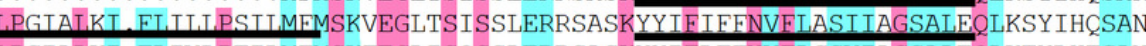

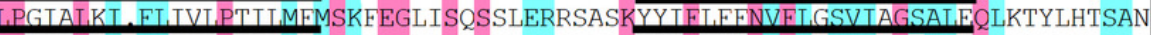

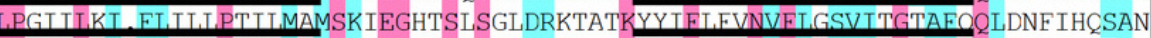

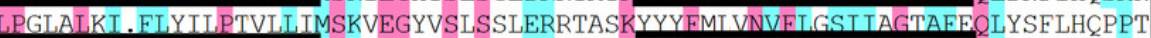

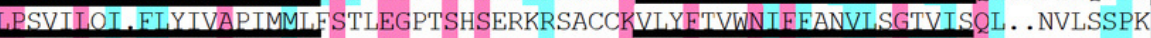
LESVITOI FIYTVIPTTMMEFSTLEGPISHSERKKSACCKVIYYETTWINVEEVNVLSGSAISQL . . NALSSPK

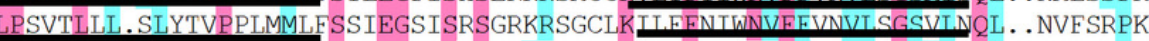
LRSVTIHV.TSSCVRSTMKIFSTMQGEVSVSGIEQSACNKMT_RETTWTAFFANVLTGSAIVQF . . EIFLNPK

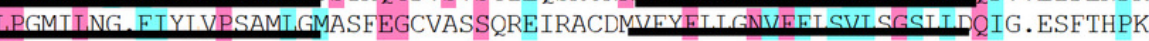
I.P.

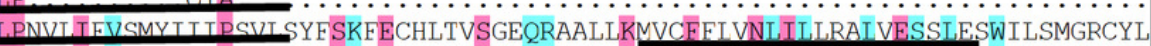

\section{TM4}

E. . . . . IPRTIGEAIPMKATFEITYTMVDGWAGVAGEILRLKPIVIFHLKNFFIVKTEKDREEAMD E. . . . . . IPRTIGEAIPMKATF EITYTMVDGWAGVAGEILRLKPIVIFHLKNFFIVKTEKDREEAMD D. . . . . IPRI IGDSIPMKATF EITYVMVDGWTGIAGEILRLKPLIFFHLKNFFIVKTEKDREEAMD K......... IPEVVGESIPMKAAF EMTYIMVDGWLGIAAEVIRLKAIVIFHIKNAFIVRTEHDRECAMD Q......... IPRTIGVAIPMKATFFMTYVMVDGWAGIANEILRVKAIVIYHLKNME IVKTERDRDRAMD D. . . . . . IFVQLAKAVPGQATFEITYVLTSGWASLSSEVMQLFGLIWNEI IKYVLR. MREDTEFVP. D......... IPMQLAKAVEVQATFFTTYVITSGWASISSEIMOIFGITWNFLRRYLLR. IKEDSDELY. D. . . . . . MPTMLAELVPKQATFF ITYVITSGWIASICSEIICVVNIVYNFFSRFVCCCHRQNKEYVY. E.......... LPSKLAVIVPAQASFEIAYVVTS.WTSITSELTQITALFCHLWGKCAKC. CKRDYSKAP. N........ IPNRLASAVSAQSDFEITYILTNGMSGESLEVLQFGLLIWQFLKARSIG . HSEEPYLY.

DGPDCKQIERYLSPSSELSRSSLSSLAFLITCTELGISFDLLAPIPWIKHIIMKKERKNDMVQLVPEENELYLP

TM5

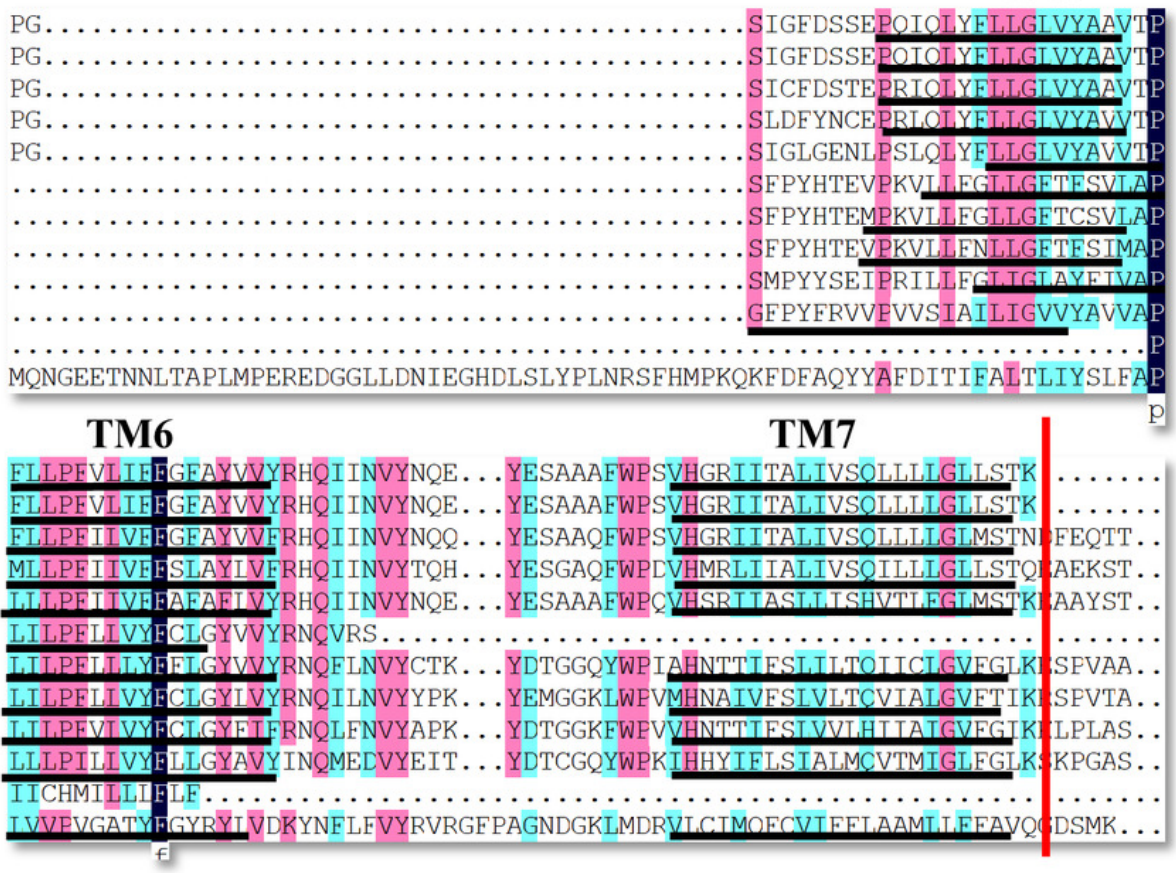




\section{Figure 5}

Expression profiles of ZmOSCAs.

(A) Expression profiles of the 12 ZmOSCA genes in fifteen tissues illustrated by a heat map. Different colors in the heat map represent the normalized gene expression values indicated by the scale bar. The color scale ranged from green, representing low expression, and passes through yellow and finally to red, representing high expression. The gray color shows missing data. (B) Expression profile of ZmOSCA genes in maize B73 seedlings under drought. Total RNA was extracted from the third leaves before and after the drought treatments. 5 and 24 hours, represent the collection time points, responding to relative leaf water content (RLWC) of $70 \%$ and $58 \%$, respectively. Transcript levels of $\mathrm{ZmUbi-2}$ were used as an internal control for data normalization. The represented mean and SD derived from three biological replicates. (t-test, ${ }^{\square} p \leq 0.05,{ }^{\square} p \leq 0.01$ ). 
A
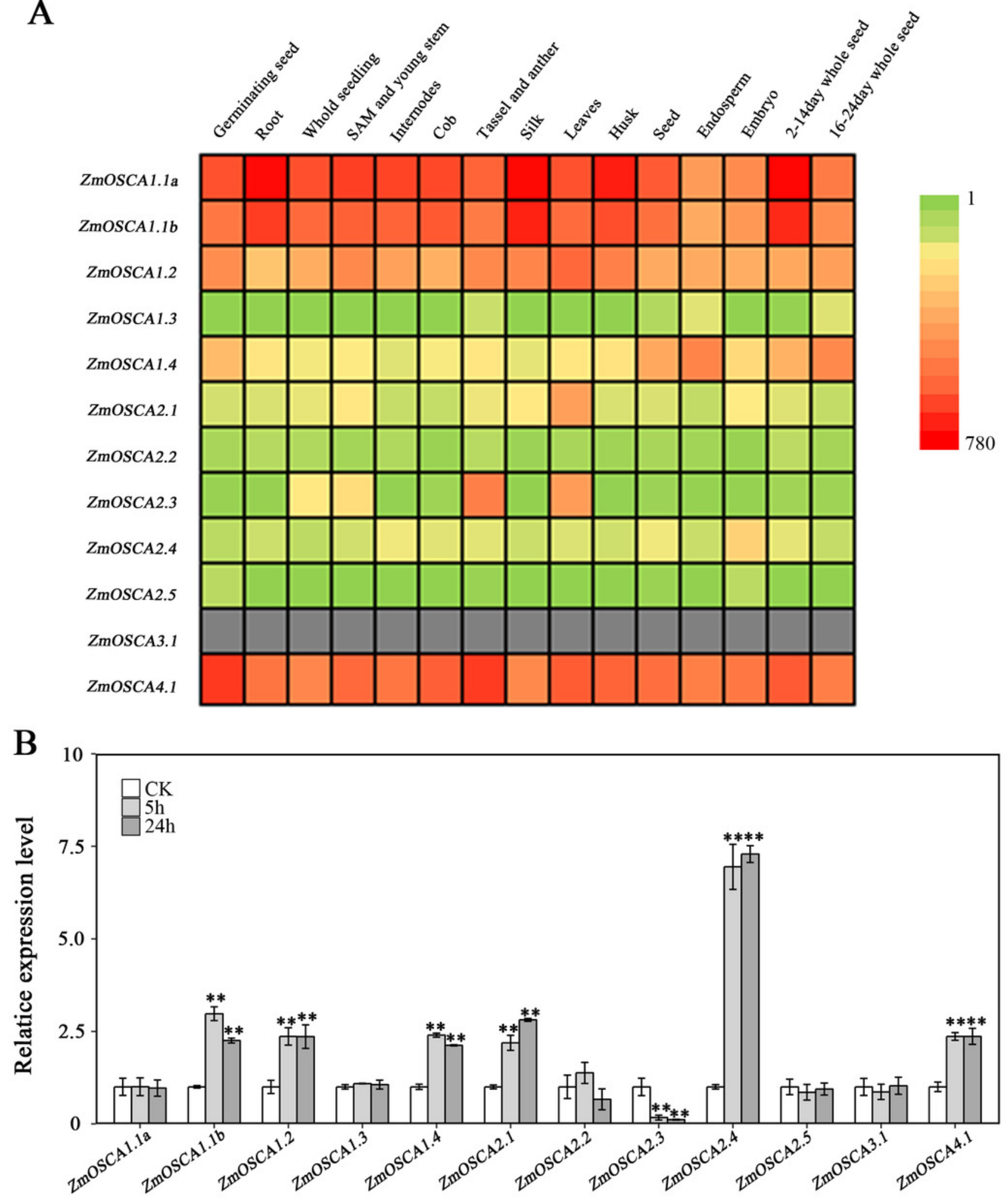
Figure 6

Expression patterns of ZmOSCA genes in maize B73 adult leaves under drought.

The drought treatment started from the (eight leaves) V8 stage, while the control was wellwatered. Total RNA was collected at V12, V14, V16 and R1 stage for both drought stressed and well-watered plants. Transcript levels of $Z m U b i-2$ transcript levels were used served as an internal control for data normalization. Data represent the represented mean and SD derived from of three biological replicates. (t-test, ${ }^{\square} \leq \leq 0.05,{ }^{\square} p \leq 0.01$ ).
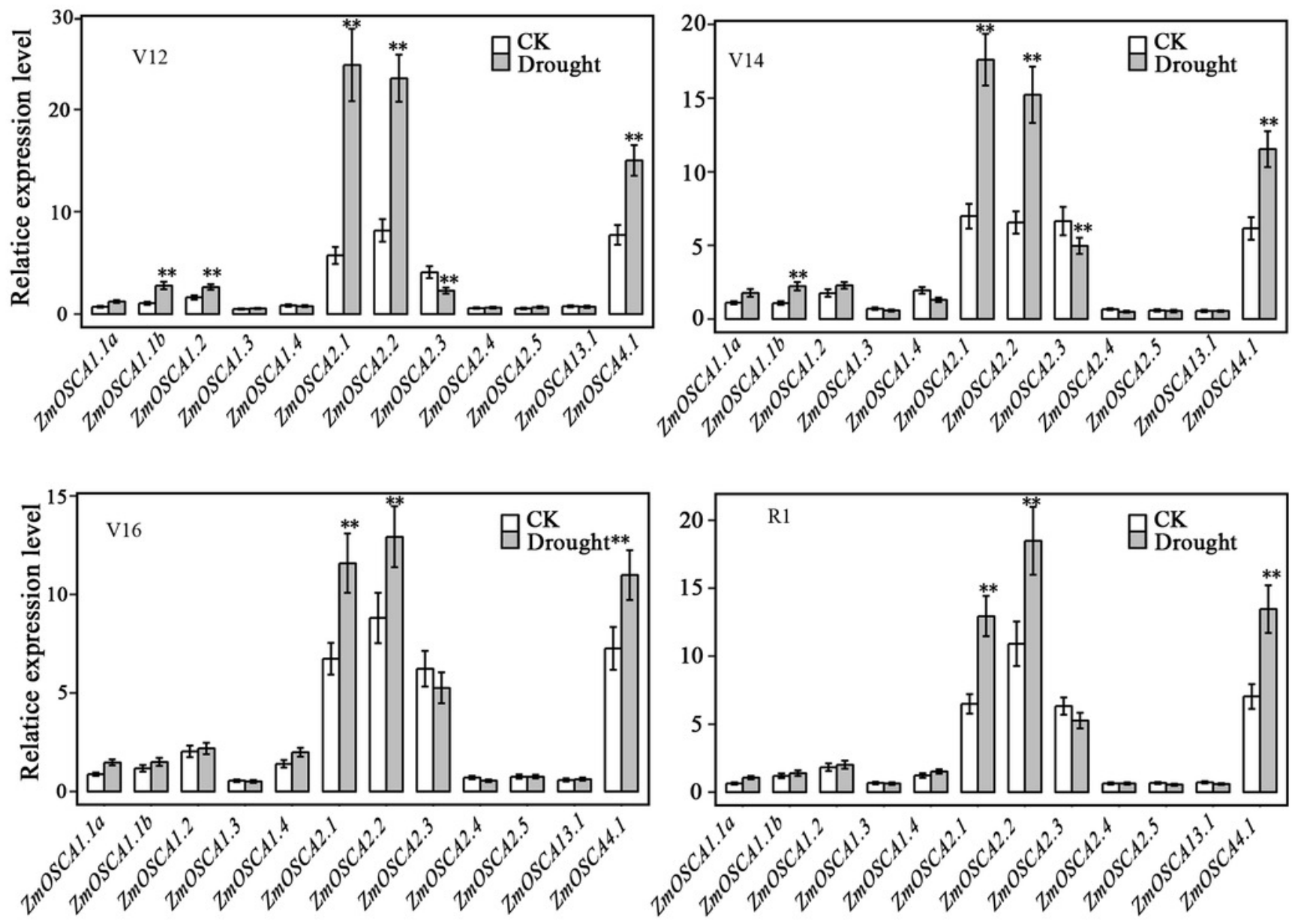


\section{Table $\mathbf{1}$ (on next page)}

Detailed information for twelve ZmOSCA genes in the Zea mays L. genome. 
Table1. Detailed information for twelve ZmOSCA genes in the Zea mays L. genome.

\begin{tabular}{ccccccc}
\hline Gene name & Gene identifier & Chromosome & $\begin{array}{c}\text { Protein } \\
\text { length } \\
(\mathrm{aa})\end{array}$ & $\begin{array}{c}\text { ORF } \\
(\mathrm{bp})\end{array}$ & $\begin{array}{c}\text { Number } \\
\text { of exons }\end{array}$ & class \\
\hline ZmOSCA1.1a & GRMZM2G064189 & 3 & 327 & 984 & 4 & 1 \\
ZmOSCA1.1b & GRMZM2G021194 & 3 & 768 & 2307 & 11 & 1 \\
ZmOSCA1.2 & GRMZM2G456000 & 8 & 768 & 2307 & 11 & 1 \\
ZmOSCA1.3 & GRMZM2G181206 & 6 & 748 & 2247 & 11 & 1 \\
ZmOSCA1.4 & GRMZM2G128641 & 1 & 810 & 2433 & 11 & 1 \\
ZmOSCA2.1 & GRMZM2G163059 & 3 & 586 & 1761 & 8 & 2 \\
ZmOSCA2.2 & GRMZM2G409093 & 1 & 765 & 2298 & 10 & 2 \\
ZmOSCA2.3 & GRMZM2G164470 & 5 & 749 & 2250 & 10 & 2 \\
ZmOSCA2.4 & GRMZM2G039186 & 1 & 699 & 2100 & 10 & 2 \\
ZmOSCA2.5 & GRMZM2G402708 & 8 & 706 & 2121 & 10 & 2 \\
ZmOSCA3.1 & GRMZM2G162253 & 5 & 249 & 750 & 2 & 3 \\
ZmOSCA4.1 & GRMZM2G059891 & 9 & 796 & 2391 & 1 & 4 \\
\hline
\end{tabular}

1 


\section{Table 2 (on next page)}

Numbers and classification of OSCA genes in Arabidopsis, rice, maize, and sorghum. 
Table 2. Numbers and classification of OSCA genes in

Arabidopsis, rice, maize, and sorghum.

\begin{tabular}{cccccc}
\hline Species & clade1 & clade2 & clade3 & clade4 & $\begin{array}{c}\text { In } \\
\text { Total }\end{array}$ \\
\hline Arabidopsis thaliana & 8 & 5 & 1 & 1 & 15 \\
Oryza sativa & 4 & 5 & 1 & 1 & 11 \\
Zea mays & 5 & 5 & 1 & 1 & 12 \\
Sorghum bicolor & 4 & 5 & 1 & 1 & 11 \\
\hline
\end{tabular}

1 


\section{Table 3(on next page)}

Number of significantly associated genetic variation in ZmOSCA genes with drought tolerance at the seedling stage. 
Table 3.Number of significantly associated genetic variation in ZmOSCA genes with drought tolerance at the seedling stage.

\begin{tabular}{cccccc}
\hline \multirow{2}{*}{ Gene ID } & Gene name & $\begin{array}{c}\text { Polymorphic } \\
\text { number* }\end{array}$ & $\mathrm{GLM}$ & $\mathrm{PC}_{2}$ & $\mathrm{PC}_{2}+\mathrm{K}$ \\
\cline { 4 - 6 } & & & $P \leqslant 0.01$ & $P \leqslant 0.01$ & $P \leqslant 0.01$ \\
\hline GRMZM2G064189 & ZmOSCA1.1a & 4 & 0 & 0 & 0 \\
GRMZM2G021194 & ZmOSCA1.1b & 22 & 0 & 0 & 0 \\
GRMZM2G456000 & ZmOSCA1.2 & 11 & 4 & 0 & 0 \\
GRMZM2G181206 & ZmOSCA1.3 & 14 & 0 & 0 & 0 \\
GRMZM2G128641 & ZmOSCA1.4 & 42 & 7 & 0 & 0 \\
GRMZM2G163059 & ZmOSCA2.1 & 12 & 2 & 0 & 0 \\
GRMZM2G409093 & ZmOSCA2.2 & 3 & 0 & 0 & 0 \\
GRMZM2G164470 & ZmOSCA2.3 & 2 & 0 & 0 & 0 \\
GRMZM2G039186 & ZmOSCA2.4 & 13 & 0 & 0 & 0 \\
GRMZM2G402708 & ZmOSCA2.5 & 4 & 0 & 0 & 0 \\
GRMZM2G162253 & ZmOSCA3.1 & 7 & 0 & 0 & 0 \\
GRMZM2G059891 & ZmOSCA4.1 & 34 & 10 & 2 & 3 \\
\hline
\end{tabular}

$*$ MAF (Minor Allele Frequency) $\geqslant 0.05$. 